\title{
Differences in Recovery of Left and Right Ventricular Function Following Aortic Valve Interventions: A longitudinal echocardiographic study in patients undergoing surgical, transapical or transfemoral aortic valve implantation
}

\section{Linköping University Post Print}

\section{Tweet}

N.B.: When citing this work, cite the original article.

This is the pre-reviewed version of the following article:

Lena M Forsberg, Eva Tamás, Farkas Vánky, Jan Engvall and Eva Nylander, Differences in Recovery of Left and Right Ventricular Function Following Aortic Valve Interventions: A longitudinal echocardiographic study in patients undergoing surgical, transapical or transfemoral aortic valve implantation, 2013, Catheterization and cardiovascular interventions, (82), 6, 1004-1014.

which has been published in final form at:

http://dx.doi.org/10.1002/ccd.24812

Copyright: Wiley-Blackwell http://eu.wiley.com/WileyCDA/Brand/id-35.html

Postprint available at: Linköping University Electronic Press http://urn.kb.se/resolve?urn=urn:nbn:se:liu:diva-81050 


\title{
Differences in Recovery of Left and Right Ventricular Function Following Aortic Valve Interventions
}

\author{
- A Longitudinal Echocardiographic Study in Patients Undergoing Surgical, \\ Transapical or Transfemoral Aortic Valve Implantation
}

Lena M Forsberg M.D. Ph.D. ${ }^{1,2}$, Éva Tamás M.D. Ph.D. ${ }^{4}$, Farkas Vánky M.D. Ph.D. ${ }^{4}$, Jan Engvall M.D. Ph.D. ${ }^{1-3}$, Eva Nylander M.D. Ph.D. ${ }^{1-3}$

${ }^{1}$ Division of Clinical Physiology, Department of Medical and Health Sciences, Faculty of Health Sciences, Linköping University, Linköping, Sweden.

${ }^{2}$ Center for Medical Image Science and Visualization, Linköping University, Linköping, Sweden.

${ }^{3}$ Department of Clinical Physiology, County Council of Östergötland, Linköping, Sweden.

${ }^{4}$ Department of Cardiothoracic Surgery, County Council of Östergötland, Sweden.

\section{Correspondence:}

Lena Forsberg

Department of Clinical Physiology

The Faculty of Health Sciences

SE-581 85, Linköping, Sweden.

E-mail: lena.forsberg@liu.se

Business telephone: +46101035660

Home telephone: +46736182330

Indexing words: Echocardiography, aortic stenosis, thoracic surgery, transcatheter aortic valve implantation

Short title: Biventricular function after TAVI or surgery 


\section{Abstract}

Objectives: To evaluate longitudinal left and right ventricular function (LVF and RVF) after transcatheter aortic valve implantation (TAVI) as compared to surgical aortic valve replacement (SAVR) and LVF and RVF after TAVI by the transfemoral (TF) or transapical (TA) approach.

Background: Knowledge about differences in recovery of LVF and RVF after TAVI and SAVR is scarce.

Methods: Sixty patients (age $81 \pm 7$ years, logistic EuroSCORE $16 \pm 10 \%$ ), undergoing TAVI (TF: $\mathrm{n}=35$ and TA: $\mathrm{n}=25$ ), were examined by echocardiography including atrioventricular plane displacement (AVPD) and peak systolic velocities (PSV) by tissue Doppler at basal RV free wall, LV lateral wall and septum preprocedurally, 7 weeks and 6 months postprocedurally. Twenty-seven SAVR-patients were matched to 27 TAVI-patients by age, gender and LVF.

Results: Early post- intervention, TAVI-patients had improved longitudinal LVF. However, when analyzed separately only TF, but not TA-patients, had improved LV lateral and septal AVPD and PSV (all $\mathrm{p} \leq 0.01$ ). All TAVI patients, as well as the TF- and TA-group had unchanged longitudinal LVF between the early and late follow ups (all p>0.05). The SAVR-group had higher septal LVF than the matched TAVI-group preprocedurally, while postoperatively this difference was diminished. Longitudinal RVF was better in the TF-group than in the TA-group pre- and postprocedurally. Although the SAVR-group had superior longitudinal RVF preoperatively, this was inferior to TAVI postoperatively.

Conclusions: Postprocedural longitudinal LVF and RVF in patients undergoing TF-TAVI, TA-TAVI or SAVR differ considerably. Preservation of longitudinal RVF after TAVI might influence the selection of aortic valve intervention in the future. ( 249 words) 


\section{Introduction}

Transcatheter aortic valve implantation (TAVI) has emerged as a new treatment option for severe aortic stenosis (AS) patients who have an estimated high surgical risk or other contraindications for surgical aortic valve replacement (SAVR). Compared to standard therapy, TAVI has demonstrated lower mortality and morbidity.(1) Moreover, in a surgical high risk patient population there was no difference in 1-year survival between SAVR and TAVI.(2)

While global systolic left ventricular function (LVF) becomes depressed late in the natural history of AS, longitudinal LVF, assessed by tissue Doppler imaging (TDI) or M-mode echocardiography, shows an early decrease.(3,4) Improved longitudinal LVF, early after SAVR and TAVI, has been shown in patients with normal global systolic LVF.(5-7)

Left ventricular (LV) diastolic dysfunction, due to increased diastolic stiffness and elevated filling pressures, has been suggested to occur before global systolic function is depressed in AS patients.(8) Reversal of diastolic dysfunction after SAVR is a slow process (years), which is why preoperative diastolic dysfunction has been proposed as a marker of postoperative irreversible LV dysfunction.(9,10) Immediate improvement in LV diastolic function has been demonstrated after TAVI but long term potential recovery in LV diastolic function remains unexplored.(11)

The transapical approach is considered to be more invasive since it involves LV puncture but it requires less catheter manipulation within the aortic arch. Furthermore, as a consequence of using transfemoral approach as default choice of intervention in patients accepted to TAVI TA patients have been suggested to have a higher risk profile due to higher frequency of comorbidities such as coronary artery disease or renal failure. $(2,12)$ It is unknown whether patients undergoing transapical and transfemoral approaches differ in postprocedural recovery of LVF. Impaired longitudinal right ventricular function (RVF) after SAVR is common.(13) However, in a previous study we showed an early recovery in longitudinal RVF after TAVI.(6) Presently there is no knowledge about midterm RVF after TAVI.

The aim of this study was to 1) evaluate early and midterm changes in systolic and diastolic LVF in patients with severe AS undergoing TAVI, including both the transfemoral and transapical 
approaches, by echocardiography and pulsed TDI; and 2) to analyze potential differences between the preservation or recovery of LV and RV function in patients undergoing TAVI and SAVR. 


\section{Methods}

\section{Patients}

The study design was prospective repeated cross sectional. From September 2008 to June 2011, 68 patients with severe AS underwent TAVI at our center. All patients were assessed by a multidisciplinary team not to be candidates for surgery due to high risk or contraindications to SAVR. Exclusion criteria were: an aortic annulus diameter smaller than $18 \mathrm{~mm}$ or larger than $25 \mathrm{~mm}$ (when a $29 \mathrm{~mm}$ prosthesis became available $27 \mathrm{~mm}$ was used as the upper limit) or survival with a reasonable quality of life or duration was unlikely. Preprocedural investigations included transthoracic and transesophageal echocardiography, coronary angiography, iliofemoral angiography and CT scan of the aorta with $3 \mathrm{D}$ reconstruction. The default approach was transfemoral with transapical as a second choice.

Eight patients were excluded due to the following reasons: administrative error $(n=3)$, refusal to take part in follow up at our center $(n=3)$, poor echocardiographic image quality $(n=1)$, chordal rupture during the TAVI procedure with severe mitral regurgitation $(n=1)$. The patients who refused follow up had a good clinical status, normal LVF and aortic valve function reported by their local cardiologist. The final study population consisted of 60 patients, who were prospectively investigated using echocardiography one day preprocedurally, as well as 7 weeks and 6 months after TAVI (study flow chart presented in fig. 1).

Twenty-seven AS patients, referred for SAVR, could be matched to 27 TAVI patients in terms of gender, age ( \pm 10 years), and LVF (normal/slightly reduced ejection fraction or moderately/severely reduced ejection fraction).

\section{Echocardiography}

All patients were examined by echocardiography (Vivid 7 ultrasound system, GE Vingmed Ultrasound, Norway) with off-line image analysis. Parameters were measured according to the appropriate guidelines.(14,15) LV ejection fraction (EF) was visually estimated by two experienced investigators on a four-grade scale, where normal systolic function corresponds to $\mathrm{EF}>50 \%$, slightly 
reduced EF $40-50 \%$, moderately reduced EF $30-39 \%$ and severely reduced <30\%. LV mass was calculated according to Devereux: $0.8 x\left(1.04 x[\text { LVEDD+PWTd }+S W T d]^{3}-L^{2}\right.$ EDD $\left.{ }^{3}\right)+0.6 \mathrm{~g}$ and was indexed to body surface area (BSA).(15) The aortic valve area was calculated from the continuity equation and indexed to BSA (AVAI). The presence and degree of aortic regurgitation (AR) and mitral regurgitation (MR) were recorded.

\section{Longitudinal LVF and RVF}

To estimate regional myocardial function, peak systolic velocity (PSV) was measured in the LV septal $\left(\mathrm{PSV}_{\mathrm{S}}\right), \mathrm{LV}$ lateral $\left(\mathrm{PSV}_{\mathrm{L}}\right)$ and $\mathrm{RV}$ free wall $\left(\mathrm{PSV}_{\mathrm{RV}}\right)$ by pulsed TDI. Early diastolic myocardial velocities (é) were also measured. The 6 x $6 \mathrm{~mm}$ sample volume was placed directly underneath the mitral or tricuspid annulus in the basal myocardium in an apical 4-chamber view. The mean value of three beats was calculated.

Systolic atrioventricular plane displacement (AVPD), measured by M-mode echocardiography was determined at the LV septal $\left(\mathrm{AVPD}_{\mathrm{S}}\right)$, LV lateral $\left(\mathrm{AVPD}_{\mathrm{L}}\right)$ and $\mathrm{RV}$ lateral annulus $\left(\mathrm{AVPD}_{\mathrm{RV}}\right)$ as previously described.(16)

\section{Classification of LV diastolic function}

Peak velocities of early (E) and late (A) diastolic filling, E/A ratio, isovolumic relaxation time (IVRT), deceleration time (DT) and pulmonary venous systolic (S) and diastolic (D) flow velocity were derived from Doppler recordings of the mitral inflow at the mitral leaflet tips and the venous inflow of the right upper pulmonary vein near the orifice. The LV diastolic function was classified by an integrated evaluation of mitral inflow data and average é-velocities by pulsed TDI from the basal septal and lateral LV walls with age-related changes taken into consideration. $(17,18)$ Normal diastolic function was defined as E/A 1-2, DT 150-200ms, IVRT 50-100ms, S $\approx$ D, é $>10 \mathrm{~cm} / \mathrm{s}$ and E/é ratio $\leq 8$. Impaired relaxation was defined as E/A ratio $<0.8$, DT $>200 \mathrm{~ms}$, IVRT $\geq 100 \mathrm{~ms}, \mathrm{~S}>\mathrm{D}$, é $<8 \mathrm{~cm} / \mathrm{s}$, and E/é ratio $<8$. Pseudonormal filling was defined as E/A ratio 0.8-1.5, $\mathrm{S}<\mathrm{D}$, é $<8 \mathrm{~cm} / \mathrm{s}$ and E/é ratio 9-12. Restrictive filling was defined as $\mathrm{E} / \mathrm{A} \geq 2.0, \mathrm{DT}<160 \mathrm{~ms}, \mathrm{~S} / \mathrm{D}<1.0$, IVRT $\leq 60 \mathrm{~ms}$ and E/é ratio $>13$. Patients with atrial fibrillation formed a fifth group. 
All TAVI patients were grouped after their preoperative é and E/é according to the $5^{\text {th }}$ and $95^{\text {th }}$ percentile of normal values.(17)

\section{TAVI procedure}

TAVI was performed under general anesthesia without cardiopulmonary bypass and with guidance of transesophageal echocardiography (TEE) and fluoroscopy. SAPIEN bioprostheses (Edwards Lifesciences Irvine, California), 23- $\mathrm{mm}, 26-\mathrm{mm}$ or $29-\mathrm{mm}$ were implanted. The retrograde transfemoral approach was assigned as the first option approach and the transapical approach was chosen if significant obstructive arteriosclerotic disease, or severe tortuosity of the aorto-ilio-femoral vessels was present. For the transapical approach an anterolateral minithoracotomy was performed followed by a needle puncture of the LV apex. Rapid pacing was performed during prosthesis deployment. At the end of the procedure the apical access was closed surgically, while the femoral access was closed by closure device ( ProGlide ${ }^{\mathrm{R}}$ )

SAVR was performed through full sternotomy and with cardiopulmonary bypass. Twelve patients underwent simultaneous coronary-aortic-bypass grafting (CABG).

\section{Statistics}

Continuous variables are expressed as mean $\pm \mathrm{SD}$ and categorical variables as numbers or percentages. Analysis of variance for repeated measurement was used to assess differences between the preoperative, 7 week and 6 month data, followed by the Bonferroni posth hoc test. Comparisons between unpaired groups were made by $\chi^{2}$-test or Fisher's exact test for categorical variables, by Mann-Whitney U-test for ordinal data and unpaired t-test for continuous variables. Comparisons between the matched TAVI group and the matched SAVR group were made by McNemar's test for categorical data, by Wilcoxon sign rank test for ordinal data and paired t-test for continuous variables. A probability value of $p \leq 0.05$ was considered significant. Data analyses were performed using SPSS 19.0. All patients gave their written informed consent prior to participation. The study complies with the Declaration of Helsinki and was approved by the Regional Ethical Review Board in Linköping. 


\section{Results}

Under each subheading data are presented in the following order: first all TAVI patients followed by transapical and transfemoral treatment separately analyzed and finally, comparison of the matched TAVI and SAVR is presented.

\section{Clinical and Valve Function Data}

Clinical characteristics are presented in table I. The procedural success rate was $100 \%$ for both the transfemoral $(n=35)$ and the transapical approaches $(n=25)$. Thirty-day mortality was $7 \%$, all deaths being in-hospital in patients undergoing transapical TAVI. Transapical patients were older, had poorer kidney function, lower BSA and higher logistic EuroSCORE preprocedurally. Due to this the transfemoral and transapical groups were considered different and were not further compared.

AVAI and mean aortic pressure gradient before TAVI were $0.30 \pm 0.10 \mathrm{~cm}^{2} / \mathrm{m}^{2}$ and $58 \pm 19 \mathrm{mmHg}$, respectively, and between the early and late follow up these variables were stable $(0.82 \pm 0.21$ vs. $0.84 \pm 0.27 \mathrm{~cm}^{2} / \mathrm{m}^{2}, \mathrm{p}=1.0 ; 11 \pm 4$ vs. $10 \pm 4 \mathrm{mmHg}, \mathrm{p}=0.7$, table I in supporting information).

AR of trivial or mild grade was detected in 88 and $81 \%$ of the patients at the 7 week and 6 month follow ups, respectively and was mainly paravalvular. No TAVI patient had more than mild AR early postprocedurally, while this was found in 2 patients at 6 months. Nine patients with MR graded as more than mild preoperatively showed a significant decrease at the 6 month follow up $(\mathrm{p}=0.011)$. Prior to SAVR, AVAI was $0.35 \pm 0.09 \mathrm{~cm}^{2} / \mathrm{m}^{2}$ and mean aortic pressure gradient $51 \pm 16 \mathrm{mmHg}$. Both AVAI and mean aortic pressure gradient were stable between the two follow ups $(0.68 \pm 0.17$ vs. $0.68 \pm 0.15 \mathrm{~cm}^{2} / \mathrm{m}^{2}, \mathrm{p}=1.0 ; 13 \pm 3$ vs. $\left.14 \pm 4 \mathrm{mmHg}, \mathrm{p}=0.6\right)$.

\section{Left Ventricular Function}

\section{Global LV function}

At the following time points: preoperatively, 7 weeks and 6 months postprocedurally, 79, 74 and 85\%, respectively, of the TAVI patients had normal global LVF. In the transapical and transfemoral groups 
68 and $87 \%$, respectively, had normal LVF preprocedurally and these proportions were unchanged postprocedurally (see table 3 in supporting information).

In the matched TAVI and SAVR groups, 80 and $92 \%$ of the patients had normal global LVF preoperatively. Postprocedurally, no significant change could be seen.

\section{LV dimensions and mass}

In all TAVI patients, LV end diastolic and end systolic dimensions and posterior wall thickness were unchanged at the two follow ups, while a significant decrease of septal thickness was observed at the early follow up and a trend towards a further decrease at the second follow up (13 \pm 3 vs. $12 \pm 3$ vs. $11 \pm 2$ $\mathrm{mm} ; \mathrm{p}=0.006$ and $\mathrm{p}=0.081$ ). LV mass indexed to BSA (LVMI) decreased significantly after TAVI (142 \pm 48 vs. $\left.127 \pm 39 \mathrm{~cm}^{3} / \mathrm{m}^{2}, \mathrm{p}=0.022\right)$ and was unchanged at the 6-month follow up $(127 \pm 39$ vs. $120 \pm 33 \mathrm{~cm}^{3} / \mathrm{m}^{2}, \mathrm{p}=1.0$ ). Both the transfemoral and the transapical groups did decrease septal thickness from preprocedurally to 6 months postprocedurally, while the decrease in LVMI did not reach statistical significance (supporting information, table II).

The SAVR group had significantly decreased LVMI 6 months postoperatively ( $126 \pm 23$ vs. $112 \pm 25$ vs. $102 \pm 17 \mathrm{~cm}^{3} / \mathrm{m}^{2}, \mathrm{p}=0.596$ and $\left.\mathrm{p}=0.002\right)$.

\section{Regional LV systolic function}

Before TAVI PSV ${ }_{\mathrm{L}}, \mathrm{PSV}_{\mathrm{S}}, \mathrm{AVPD}_{\mathrm{L}}$ and $\mathrm{AVPD}_{\mathrm{S}}$ were $5 \pm 2 \mathrm{~cm} / \mathrm{s}, 4 \pm 1 \mathrm{~cm} / \mathrm{s}, 10 \pm 3 \mathrm{~mm}$ and $7 \pm 3 \mathrm{~mm}$, respectively. At the first follow up, there was a significant increase in longitudinal function in both the lateral $\left(\mathrm{PSV}_{\mathrm{L}} 6 \pm 2 \mathrm{~cm} / \mathrm{s}, \mathrm{p}<.001\right.$ and $\left.\mathrm{AVPD}_{\mathrm{L}} 11 \pm 3 \mathrm{~mm}, \mathrm{p}=0.010\right)$ and septal $\mathrm{LV}$ walls $\left(\mathrm{PSV}_{\mathrm{S}} 5 \pm 2 \mathrm{~cm} / \mathrm{s}\right.$, $\mathrm{p}<0.001$ and $\mathrm{AVPD}_{\mathrm{S}} 8 \pm 3 \mathrm{~mm}, \mathrm{p}=0.009$ ). Between the early and late postoperative examinations, longitudinal LVF remained unchanged (all $\mathrm{p}>0.05$ ).

The transapical group had unchanged longitudinal function at the two postoperative visits (Fig. 2, all $\mathrm{p}>0.05$ ), while patients in the transfemoral group increased their longitudinal function in both the septal $\left(\mathrm{AVPD}_{\mathrm{S}} \mathrm{p}=0.003\right.$, and $\left.\mathrm{PSV}_{\mathrm{S}} \mathrm{p}<.001\right)$ and lateral walls $\left(\mathrm{AVPD}_{\mathrm{L}} \mathrm{p}=0.023\right.$ and $\left.\mathrm{PSV}_{\mathrm{L}} \mathrm{p}=0.001\right)$ early postprocedurally. This was unchanged between the two follow up visits. 
Preoperatively, the SAVR group had higher $\mathrm{AVPD}_{\mathrm{S}}$ and $\mathrm{PSV}_{\mathrm{S}}$ than the matched TAVI group did. Postoperatively, the SAVR group had improved $\mathrm{AVPD}_{\mathrm{L}}$ and $\mathrm{PSV}_{\mathrm{L}}$, while the septal wall remained unchanged (Fig. 3). The difference in LV septal long axis function between the two matched groups was reduced at the early follow up, and SAVR had superior lateral LVF.

\section{LV diastolic function}

The improvement seen among TAVI patients between the preoperative and 6 month postoperative examinations was mainly due to more frequent normal diastolic function and fewer patients with a pseudonormal filling pattern (Fig. 4). The early increase of é-septal and é-lateral was, at 6 months, only seen in the septal LV wall (Table II). Six months postoperatively, E/é-septal, but not E/é-lateral, had decreased. When analyzing the TAVI patients grouped after previously published reference values for é-septal, é-lateral, E/é-septal and E/é-lateral, only patients with preprocedural abnormal é or E/é showed improvement (Fig. 5).(17)

When analyzing the two TAVI approaches separately, the patients in the transfemoral group showed improved diastolic function after the intervention, while patients in the transapical group did not (Fig. 4). É and E/é did not change significantly in the transapical group, while transfemoral patients had an increased é-septal and é-lateral, and decreased E/é-septal postprocedurally (Table II).

The SAVR group did not improve diastolic function class significantly postoperatively, but é-lateral increased and E/é-lateral diminished (Table II). At all examinations the SAVR group had better LV diastolic function class than the matched TAVI group (Fig. 4, all $\mathrm{p}<0.01$ ). Preoperatively, SAVR patients had higher é-lateral and lower E/é-septal, while postoperative differences between the two matched groups were only seen in the lateral wall.

\section{Longitudinal RVF}

Seven weeks after TAVI, $P_{\mathrm{RV}}$ increased from $9 \pm 3$ to $11 \pm 3 \mathrm{~cm} / \mathrm{s}(\mathrm{p}=0.001)$, while $\mathrm{AVPD}_{\mathrm{RV}}$ was unchanged ( $16 \pm 5$ vs. $16 \pm 5, \mathrm{p}=\mathrm{ns})$. Neither PSV nor AVPD displayed a significant change between the early and late follow up. The transfemoral and transapical groups had unchanged $A V P D_{R V}$ 
postprocedurally while the transfemoral group improved $\mathrm{PSV}_{\mathrm{RV}}$ early postprocedurally $(\mathrm{p}=0.004$, fig. 2)

Although the matched SAVR group had better longitudinal RV function than the TAVI patients preoperatively, this difference was markedly reduced postoperatively and was even lower than in TAVI patients when examined by PSV (Fig. 3). At the 6 month follow up, a significant but incomplete recovery of $A V P D_{R V}$ was observed in the SAVR group ( $\left.\mathrm{p}=0.009\right)$. 


\section{Discussion}

This is the first prospective study to explore regional LVF and RVF in patients undergoing TAVI by the transapical or transfemoral approach with a matched SAVR cohort. Our main findings were 1) patients undergoing TAVI had improved longitudinal LVF 7 weeks and 6 months after the procedure; 2) when analyzed separately, this was due to an improved postprocedural longitudinal LV systolic function among transfemoral patients; 3) LV diastolic function improved six months after TAVI; 4) longitudinal RVF was preserved after TAVI while being markedly decreased in patients undergoing SAVR.

\section{Longitudinal LV function and aortic valve intervention}

Longitudinal LVF is depressed early in AS patients despite a normal LVEF. This holds for both asymptomatic and symptomatic patients and provides prognostic information regarding the risk of future symptoms, need of SAVR, or death. $(3,19)$ The early involvement of long axis variables has been proposed to be due to the vulnerability of the subendocardial fibers to ischemia associated with LV hypertrophy and to wall stress due to increased afterload.(3) Immediately and one week after aortic valve intervention, an increase in PSV and AVPD has been found before changes in LV mass were detected.(5,7) This very early improvement in longitudinal LVF without a decrease of LV mass has been proposed to be due to the immediate afterload reduction. Seven weeks after intervention, we could confirm an improvement in longitudinal LVF after TAVI with a concurrent decrease in LV mass, indicating that myocardial remodeling also contributes to these early changes in longitudinal function. Moreover, we could also show that this improvement in regional function, as seen in the present study was stable up until at least six months after TAVI.

Transapical patients did not increase their longitudinal LVF after TAVI. This could be due to irreversible LV dysfunction caused by long standing AS or coronary artery disease. In contrast to our findings, a group of transapical patients displayed a modest increase in longitudinal LVF 6 weeks after TAVI.(20) That center did not have access to the transfemoral approach as an alternative, which could 
indicate that the absent increase of longitudinal function we found in the transapical group was due to our selection process where the transfemoral approach was the first choice. This is further supported by the difference in clinical characteristics between the two groups where the transapical group appeared as a subgroup with more severe co-morbidities. However, in the present study we cannot rule out a possible influence on cardiac motion or myocardial damage caused by surgical opening of the pericardium as part of transapical TAVI.

Prior to intervention, there was no difference in $\mathrm{AVPD}_{\mathrm{L}}$ and $\mathrm{PSV}_{\mathrm{L}}$ between SAVR and TAVI, while after surgery the lateral longitudinal LVF was significantly higher in SAVR than TAVI patients. On the other hand, the initial significant difference between these groups in septal longitudinal function diminished after intervention. These regional differences could probably be explained by the paradoxical septal motion, frequently occurring after open heart surgery.(21)

\section{LV diastolic function and aortic stenosis}

LV diastolic dysfunction is observed in AS patients before impairment of global systolic LVF. Awareness of the importance to assess diastolic function in the natural history of AS has increased during recent years. $(4,8,19)$ We found an improvement in diastolic functional class in patients undergoing TAVI, 6 months after intervention. Wall velocity (é) increased early after TAVI, which could be interpreted in terms of an improvement in myocardial relaxation. E/é has previously been proposed to be a useful marker of LV filling pressures in AS patients. In the present study, E/e' decreased at 6 months, which suggests a reduction in filling pressure. $(4,22)$ Furthermore, we could show that patients with indirect signs of disturbed LV relaxation or increased LV filling pressure estimated as é and E/é before TAVI improved early after the procedure. Nevertheless, this patient category continued to have lower é and higher E/é than patients with preprocedural values within the normal range. These measures may thus identify patients at risk of irreversible LV dysfunction.

Patients accepted to SAVR had better LV diastolic function both before and after surgery, according to the classification, than the matched TAVI patients did. However, when using TDI, differences in the response of the lateral and septal LV wall to the aortic valve intervention could be observed. These regional differences in diastolic function could be related to the paradoxical septal motion seen after 
cardiothoracic surgery but not after catheter intervention.(6,21) Findings of an increase in é in the lateral but not the septal LV wall after SAVR have been published earlier.(7)

\section{Longitudinal Right Ventricular Function and Aortic Valve Surgery}

Depressed longitudinal RVF and abnormal septal motion after open heart surgery are known phenomena, although the exact mechanism is unclear.(7,13,21) We have, consistent with a previous report, shown that while SAVR decreases PSV and AVPD in the RV free wall, TAVI patients display either preserved or increased longitudinal function early after TAVI. $(6,20,23)$ In this study we could, for the first time, show that this initial change in RV function after TAVI was stable 6 months later. Since longitudinal RVF closely correlates with RVEF, PSV and AVPD in the free wall are often used to evaluate RVF. $(24,25)$ Although 3D echocardiographic studies have found that the overall RVF is not depressed after open heart surgery, depressed longitudinal RVF must be taken into consideration when evaluating postoperative patients.(26) TAVI seems to leave longitudinal RVF unaffected, which is an important finding in an era of less invasive cardiac intervention.

\section{Limitations}

The study is limited by a relatively small sample size which precluded further subgroup analysis of longitudinal LVF in patients with atrial fibrillation or coronary artery disease. There were preprocedural differences in LVF and clinical characteristics between patients undergoing transfemoral or transapical TAVI which potentially could have had impact on postprocedural myocardial function. This could, at least partly, be explained by the selection process where the transfemoral approach was preferred when possible. Still however, the main aim of the study was to investigate potential changes in regional myocardial function after the two approaches and this could be appropriately analyzed by the used statistical methods. Although the SAVR patient cohort was matched to TAVI patients according to age, gender and LVF, the results should be interpreted with caution due to other essential unmatched differences in preinterventional clinical characteristics. 
Pulsed TDI is clinically available and has shown satisfying reproducibility. However the technique is limited by the angle dependency and the possibility that velocities recorded are influenced by global heart motion.

\section{Conclusion}

Our data suggest that the early improvement in longitudinal LVF after TAVI is stable 6 months postprocedurally. Moreover, there is a considerable difference in the response of longitudinal LV and $\mathrm{RV}$ function between patients assigned to either the transapical or the transfemoral aortic valve implantation approach. Transapical patients have been suggested to represent a patient population with higher surgical risk and we demonstrate that longitudinal LV and RV function did not improve significantly after transapical aortic valve implantation, suggesting irreversible ventricular dysfunction in this patient category. Yet, we cannot rule out that the differences between the approaches are procedure related.

Furthermore, the current study shows that TAVI avoids the reduction in longitudinal RVF frequently seen after SAVR. This could have a clinical impact for those patients with preoperative lowered RV function. Further studies are needed to examine if that patient category is favored by less invasive interventional approaches.

\section{Acknowledgements}

We thank study nurse Inger Huljebrant for her skillful help in organizing patient flow and Miriam Johansson, medical technician, for performing the echocardiographic studies.

\section{Funding Sources}

The study was financially supported by the Swedish Heart Lung Foundation, Medical Research Council of Southeast Sweden and ALF Grants from the County Council of Östergötland, Sweden. 


\section{Disclosures}

No disclosures to declare. 


\section{References}

1. Leon MB, Smith CR, Mack M, Miller DC, Moses JW, Svensson LG, Tuzcu EM, Webb JG, Fontana GP, Makkar RR and others. Transcatheter Aortic-Valve Implantation for Aortic Stenosis in Patients Who Cannot Undergo Surgery. N Eng J Med 2010;363(17):1597-1607.

2. Smith CR, Leon MB, Mack MJ, Miller DC, Moses JW, Svensson LG, Tuzcu EM, Webb JG, Fontana GP, Makkar RR and others. Transcatheter versus surgical aortic-valve replacement in high-risk patients. N Engl J Med 2011;364(23):2187-98.

3. Takeda S, Rimington H, Smeeton N, Chambers J. Long axis excursion in aortic stenosis. Heart 2001;86(1):52-6.

4. Bruch C, Stypmann J, Grude M, Gradaus R, Breithardt G, Wichter T. Tissue Doppler imaging in patients with moderate to severe aortic valve stenosis: clinical usefulness and diagnostic accuracy. Am Heart J 2004;148(4):696-702.

5. Bauer F, Benigno S, Lemercier M, Tapiero S, Eltchaninoff H, Tron C, Baala B, Brunet D, Cribier A. Early improvement of left ventricular function after implantation of a transcutaneous aortic valve: A tissue Doppler ultrasound study. Arch Cardiovasc Dis 2009;102(4):311-8.

6. Forsberg LM, Tamas E, Vanky F, Nielsen NE, Engvall J, Nylander E. Left and right ventricular function in aortic stenosis patients 8 weeks post-transcatheter aortic valve implantation or surgical aortic valve replacement. Eur J Echocardiogr 2011;12(8):603-11.

7. Lindqvist P, Bajraktari G, Molle R, Palmerini E, Holmgren A, Mondillo S, Henein MY. Valve replacement for aortic stenosis normalizes subendocardial function in patients with normal ejection fraction. Eur J Echocardiogr 2010;11(7):608-13.

8. Hess OM, Villari B, Krayenbuehl HP. Diastolic dysfunction in aortic stenosis. Circulation 1993;87(5 Suppl):IV73-6. 
9. Gjertsson P, Caidahl K, Farasati M, Oden A, Bech-Hanssen O. Preoperative moderate to severe diastolic dysfunction: a novel Doppler echocardiographic long-term prognostic factor in patients with severe aortic stenosis. J Thorac Cardiovasc Surg 2005;129(4):890-6.

10. Villari B, Vassalli G, Monrad ES, Chiariello M, Turina M, Hess OM. Normalization of diastolic dysfunction in aortic stenosis late after valve replacement. Circulation 1995;91(9):2353-8.

11. Goncalves A, Marcos-Alberca P, Almeria C, Feltes G, Rodriguez E, Hernandez-Antolin RA, Garcia E, Maroto L, Fernandez Perez C, Silva Cardoso JC and others. Acute left ventricle diastolic function improvement after transcatheter aortic valve implantation. Eur $\mathbf{J}$ Echocardiogr 2011;12(10):790-7.

12. Thomas M, Schymik G, Walther T, Himbert D, Lefevre T, Treede H, Eggebrecht H, Rubino P, Michev I, Lange R and others. Thirty-day results of the SAPIEN aortic Bioprosthesis European Outcome (SOURCE) Registry: A European registry of transcatheter aortic valve implantation using the Edwards SAPIEN valve. Circulation 2010;122(1):62-9.

13. Wranne B, Pinto FJ, Hammarstrom E, St Goar FG, Puryear J, Popp RL. Abnormal right heart filling after cardiac surgery: time course and mechanisms. Br Heart J 1991;66(6):435-42.

14. Quinones MA, Otto CM, Stoddard M, Waggoner A, Zoghbi WA. Recommendations for quantification of Doppler echocardiography: a report from the Doppler Quantification Task Force of the Nomenclature and Standards Committee of the American Society of Echocardiography. J Am Soc Echocardiogr 2002;15(2):167-84.

15. Lang RM, Bierig M, Devereux RB, Flachskampf FA, Foster E, Pellikka PA, Picard MH, Roman MJ, Seward J, Shanewise JS and others. Recommendations for chamber quantification: a report from the American Society of Echocardiography's Guidelines and Standards Committee and the Chamber Quantification Writing Group, developed in conjunction with the European Association of Echocardiography, a branch of the European Society of Cardiology. J Am Soc Echocardiogr 2005;18(12):1440-63. 
16. Carlhall CJ, Lindstrom L, Wranne B, Nylander E. Atrioventricular plane displacement correlates closely to circulatory dimensions but not to ejection fraction in normal young subjects. Clin Physiol 2001;21(5):621-8.

17. Munagala VK, Jacobsen SJ, Mahoney DW, Rodeheffer RJ, Bailey KR, Redfield MM. Association of newer diastolic function parameters with age in healthy subjects: a populationbased study. J Am Soc Echocardiogr 2003;16(10):1049-56.

18. Nagueh SF, Appleton CP, Gillebert TC, Marino PN, Oh JK, Smiseth OA, Waggoner AD, Flachskampf FA, Pellikka PA, Evangelista A. Recommendations for the evaluation of left ventricular diastolic function by echocardiography. J Am Soc Echocardiogr 2009;22(2):10733.

19. Lancellotti P, Moonen M, Magne J, O'Connor K, Cosyns B, Attena E, Donal E, Pierard L. Prognostic effect of long-axis left ventricular dysfunction and B-type natriuretic peptide levels in asymptomatic aortic stenosis. Am J Cardiol 2010;105(3):383-8.

20. Zhao Y, Lindqvist P, Nilsson J, Holmgren A, Naslund U, Henein MY. Trans-catheter aortic valve implantation--early recovery of left and preservation of right ventricular function. Interact Cardiovasc Thorac Surg 2011;12(1):35-9.

21. Reynolds HR, Tunick PA, Grossi EA, Dilmanian H, Colvin SB, Kronzon I. Paradoxical septal motion after cardiac surgery: a review of 3,292 cases. Clin Cardiol 2007;30(12):621-3.

22. Gotzmann M, Lindstaedt M, Bojara W, Mugge A, Germing A. Hemodynamic results and changes in myocardial function after transcatheter aortic valve implantation. Am Heart $\mathbf{J}$ 2010;159(5):926-32.

23. Kempny A, Diller GP, Kaleschke G, Orwat S, Funke A, Schmidt R, Kerckhoff G, Ghezelbash F, Rukosujew A, Reinecke H and others. Impact of transcatheter aortic valve implantation or surgical aortic valve replacement on right ventricular function. Heart 2012;98(17):1299-304.

24. Meluzin J, Spinarova L, Bakala J, Toman J, Krejci J, Hude P, Kara T, Soucek M. Pulsed Doppler tissue imaging of the velocity of tricuspid annular systolic motion; a new, rapid, and non-invasive method of evaluating right ventricular systolic function. Eur Heart $\mathbf{J}$ 2001;22(4):340-8. 
25. Kaul S, Tei C, Hopkins JM, Shah PM. Assessment of right ventricular function using twodimensional echocardiography. Am Heart J 1984;107(3):526-31.

26. Tamborini G, Muratori M, Brusoni D, Celeste F, Maffessanti F, Caiani EG, Alamanni F, Pepi M. Is right ventricular systolic function reduced after cardiac surgery? A two- and threedimensional echocardiographic study. Eur J Echocardiogr 2009;10(5):630-4. 


\section{Legends}

Fig. 1

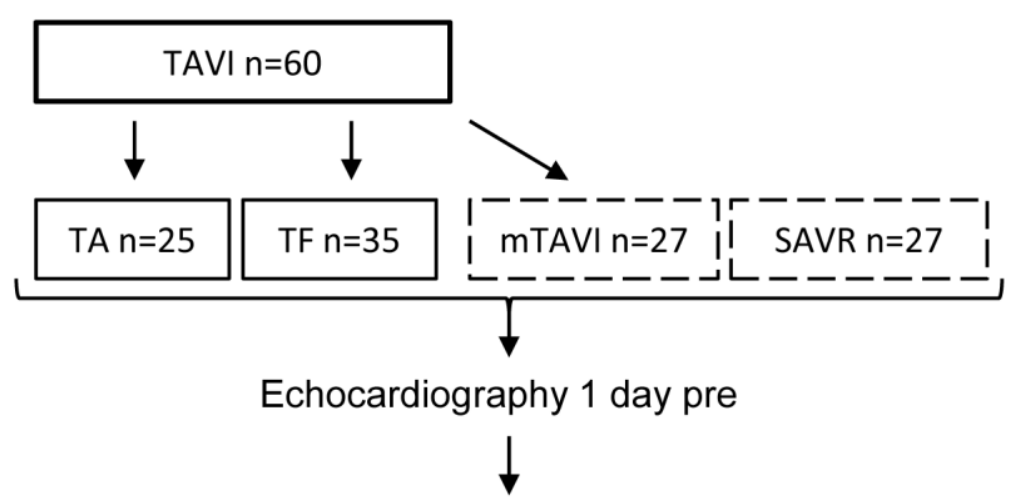

Aortic valve intervention

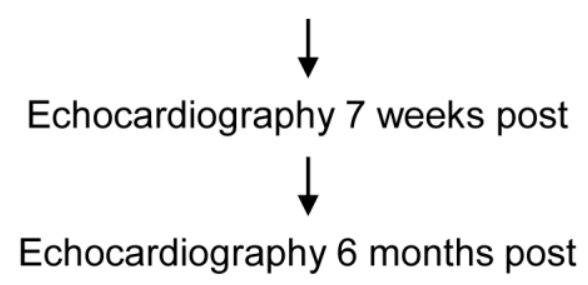

Figure 1

Study flow chart. TA; transapical, TF; transfemoral, mTAVI; matched TAVI. 
Fig. 2
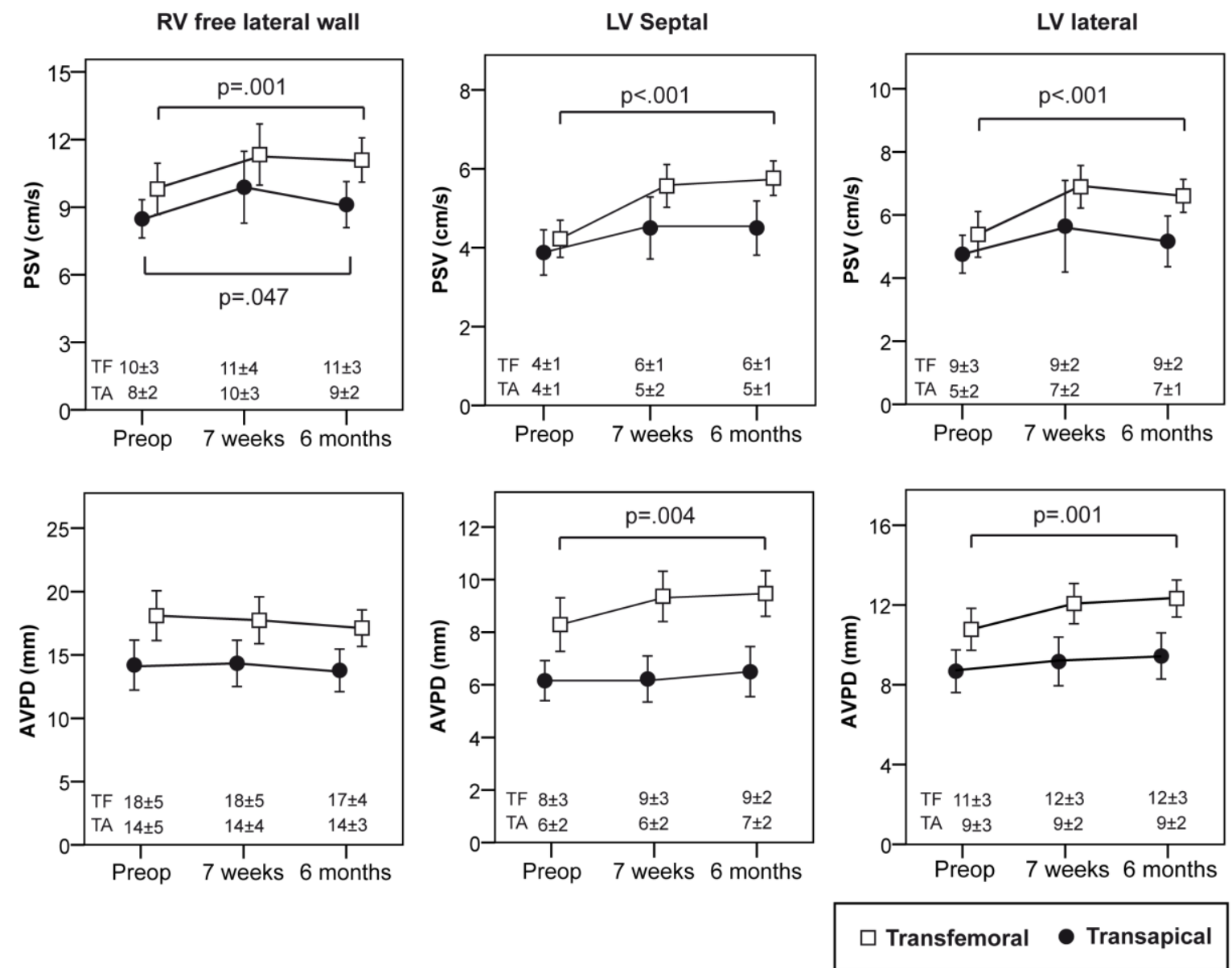

Figure 2

Left and right ventricular longitudinal function as peak systolic velocity (PSV) and atrioventricular displacement (AVPD) in transapical (black circles) and transfemoral (white cubes) patients one day preprocedurally, seven weeks and six months postprocedurally. Data are presented as mean and $95 \%$ $\mathrm{CI}$ and as mean $\pm \mathrm{SD}$ in the bottom of the figure. $\mathrm{P}$-values in the figure are from repeated measurement ANOVA. TA; transapical, TF; transfemoral. 
Figure 3

RV free lateral wall
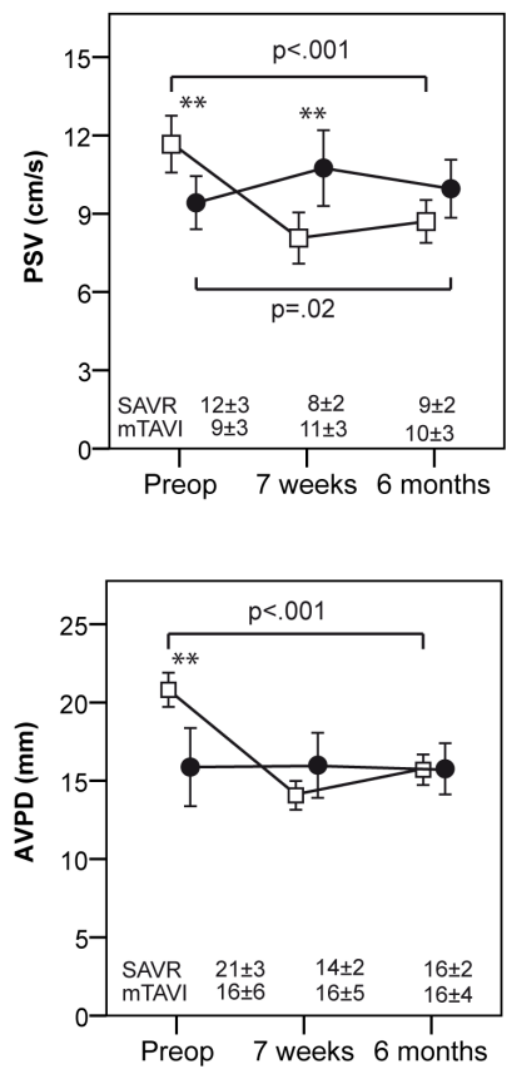

LV Septal
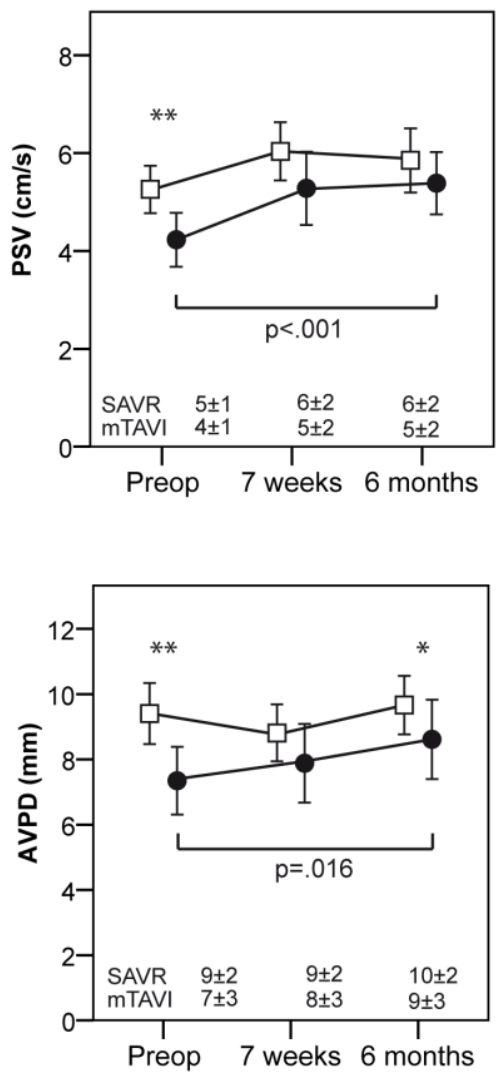

LV lateral
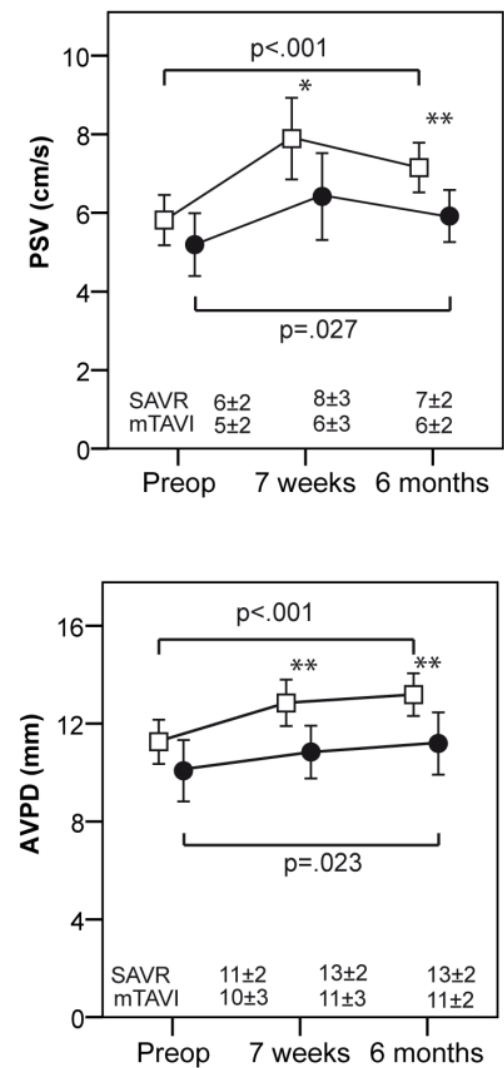

$\square$ SAVR • mTAVI

Figure 3

Left and right ventricular longitudinal function as peak systolic velocity (PSV) and atrioventricular displacement (AVPD) in matched patients undergoing transcatheter aortic valve implantation (mTAVI, black circles) or surgical aortic valve replacement (SAVR, white cubes) patients one day preprocedurally, 7 weeks and 6 months postprocedurally. Data are presented as mean and 95\% CI and as mean $\pm \mathrm{SD}$ in the bottom of the figure. $\mathrm{P}$-values in the figure are from repeated measurement ANOVA. mTAVI vs. SAVR: ${ }^{*} \mathrm{p}<0.05,{ }^{* *} \mathrm{p}<0.01$ 
Figure 4

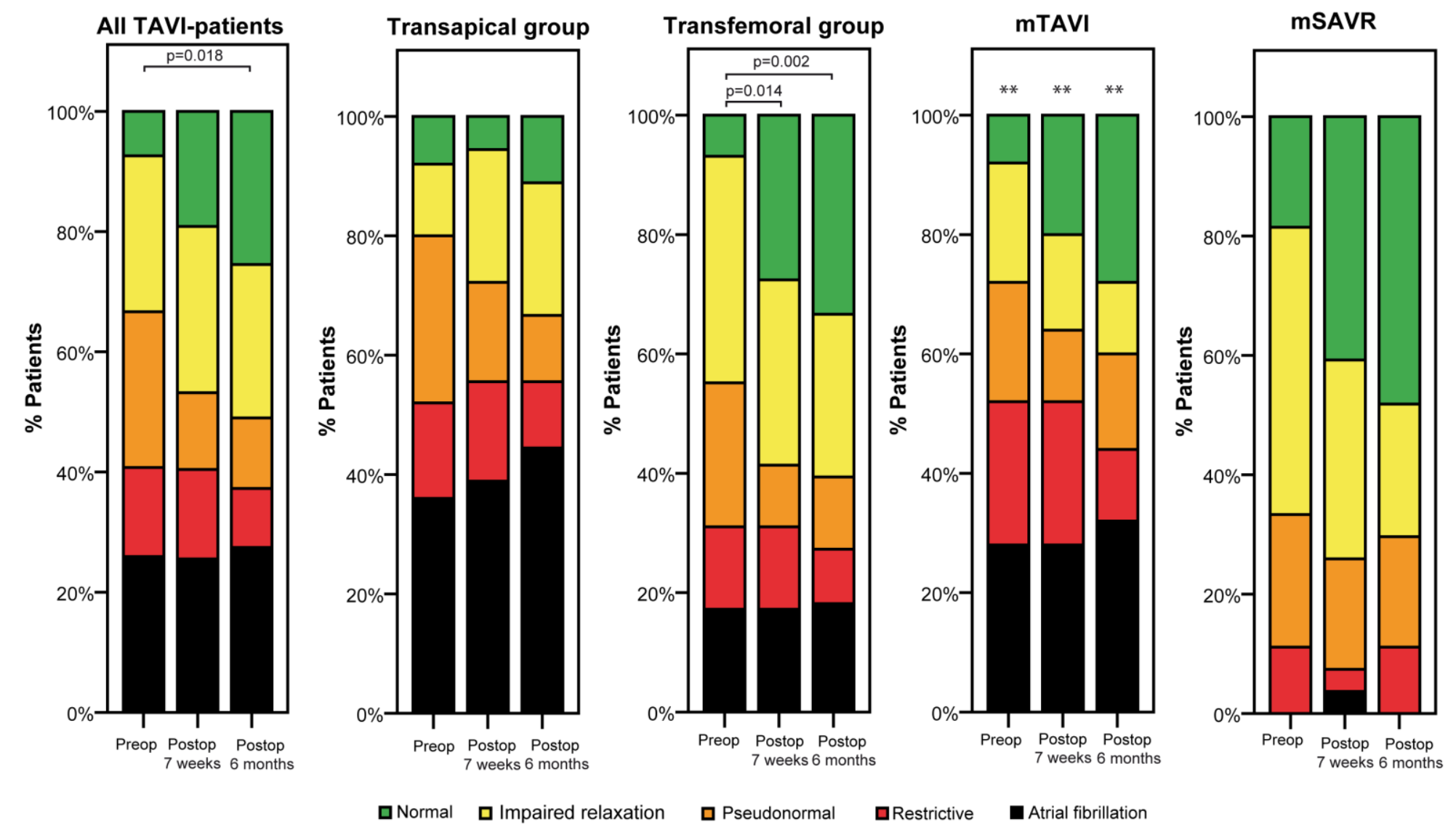

Figure 4

Patients in different subclasses of diastolic function preoperatively, early postoperatively and late postoperatively. Patients with missing examinations (n=4) preoperatively are excluded. TAVI-patients who died during follow up had preoperatively impaired relaxation $(\mathrm{n}=1)$, pseudonormal pattern ( $\mathrm{n}=1)$, restrictive pattern $(\mathrm{n}=1)$ and atrial fibrillation $(\mathrm{n}=3)$. TAVI vs SAVR: **p<0.01 
Figure 5

É-septal $<5(\bullet)$ or $>5$ (०) preop

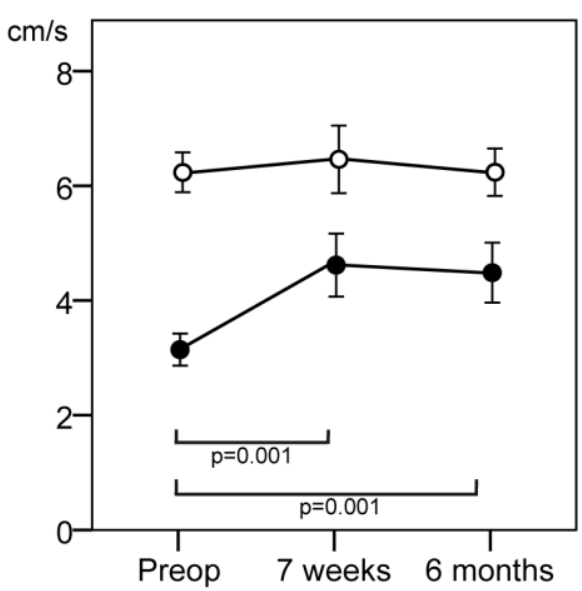

É-lateral $<5(\bullet)$ or $>5$ (o) preop

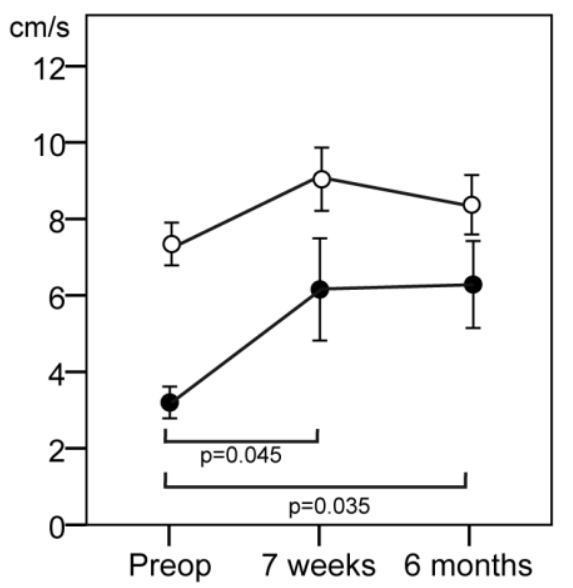

Elé lateral $<14$ (0) or $>14(\bullet)$ preop

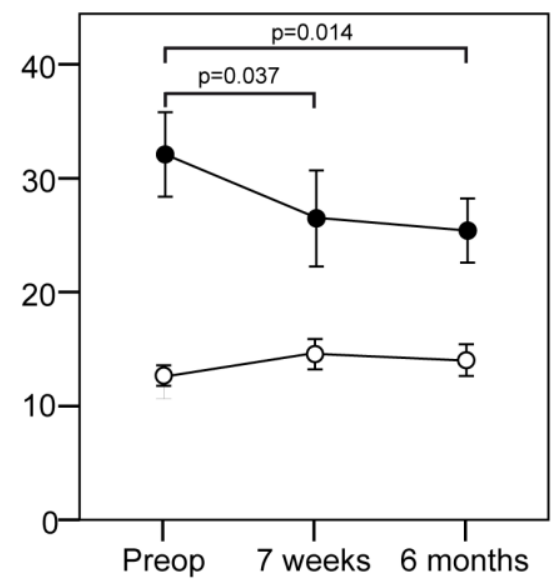

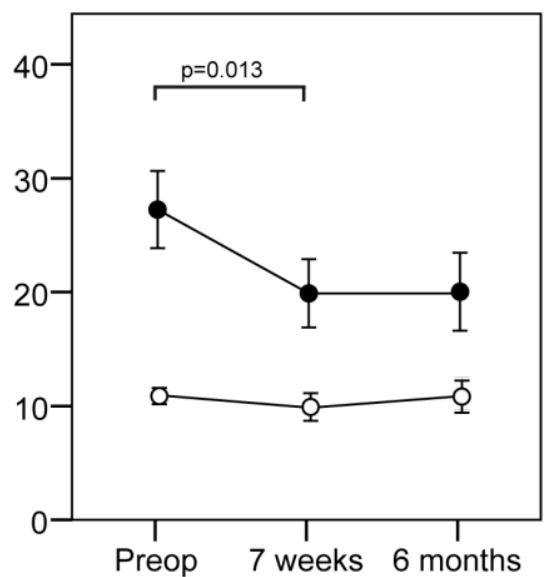

Figure 5

É and E/é from the septal and lateral left ventricular (LV) walls in all TAVI-patients subdivided after preoperative é and E/é according to earlier published normal values for the corresponding LV wall.(17) Patients with preoperative abnormal é or E/é show changes towards normalization during follow up. The normal (o) groups differ significantly from the abnormal (•) groups at all occasions $(\mathrm{p}<0.05)$ 